ojs.uv.es/index.php/qfilologia/index

Rebut: 16.06.2020. Acceptat: 09.09.2020

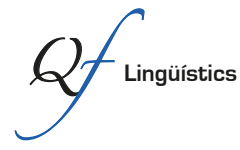

Per a citar aquest article: Dallemole, Jussara \& Osório, Paulo. 2020. "História e compilação lexicográfica na análise do campo semântico 'Convívio e Comportamento Social': alguns contributos para o estudo da variação em PE e PB”. Quaderns de Filologia: Estudis Lingüístics XXV: 75-97.

doi: $10.7203 /$ Q.25.19070

\title{
História e compilação lexicográfica na análise do campo semântico "Convívio e Comportamento Social": alguns contributos para o estudo da variação em PE e PB
}

\author{
Lexicographic compilation and History in the analysis of the semantic field \\ "Conviviality and Social Behaviour": some contributions for the study of variation \\ in European Portuguese and Brazilian Portuguese
}

\author{
Jussara DAllemole \\ Instituto Federal de Mato Grosso \\ jussarapettenon@gmail.com \\ PAulo Osório \\ Universidade da Beira Interior \\ pjtrso@ubi.pt
}

Resumo: Este estudo, descritivo-contrastivo de âmbito semântico-lexical, entre Português Europeu (PE) e Português do Brasil (PB), toma, respetivamente, a análise em duas regiões geográficas: Covilhã (Portugal) e Cuiabá (Brasil). A investigação assenta na história e na variação semântico-lexical de aspetos respeitantes ao campo semântico "Convívio e Comportamento Social” do questionário semântico-lexical (QSL) aplicado a informantes de ambas as zonas geográficas. A análise dos dados permitiu evidenciar que os falares não se manifestaram completamente distintos do léxico de outras regiões brasileiras e portuguesas, de acordo com a pesquisa realizada no Tesouro do Léxico Patrimonial Galego e Portugués (TLPGP).

Palavras chave: geolinguística; sociolinguística; semântica lexical; variação linguística.

Abstract: This semantic-lexical descriptive-contrastive study, between European Portuguese $(\mathrm{PE})$ and Brazilian Portuguese (PB), aims respectively to analyse two geographic regions: Covilhã (Portugal) and Cuiabá (Brazil). This investigation is based on the history and the

\footnotetext{
${ }^{\mathrm{I}}$ Este estudo integra-se numa investigação mais ampla que tem efetuado a análise semântico-lexical de diferentes campos semânticos dos mesmos pontos geográficos. Deste modo, este texto, embora utilize enquadramentos teóricos, metodológicos e instrumentos já utilizados, particulariza-se pela análise do campo semântico "Convívio e Comportamento Social".
} 
semantic-lexical variation of aspects concerning the semantic field "Socializing and Social Behavior" of the Semantic-Lexical Questionnaire (QSL) applied to informants from both geographical areas. The analysis of data allowed us to outline that the speeches were not completely different from the lexicon of other Brazilian and Portuguese regions, according to the research carried out at the Tesouro do Léxico Patrimonial Galego e Portugués (TLPGP).

Keywords: geolinguistics; sociolinguistics; lexical semantics; linguistic variation.

\section{Introdução}

Os estudos dialetológicos são elaborados a partir do método geolinguístico, levando-se a cabo o registo das formas linguísticas por meio de pesquisas in loco, no espaço geográfico ao qual os fenómenos pertencem. Com base em estudos cartográficos, a geografia linguística aperfeiçoou o seu método de investigação, passando a contemplar particularidades etnográficas e variações diastráticas. Esta investigação tem, assim, como objetivo realizar um estudo descritivo-contrastivo, de âmbito semântico-lexical, entre o falar cuiabano (no Brasil) e o covilhanense (em Portugal). Documenta-se a variedade linguística, sob a forma cartográfica para ambos os pontos linguísticos, utilizando-se o método analítico que contrasta entre si os falares descritos e os relaciona com o conceito proposto pelo Questionário Semântico Lexical (QSL) do Projeto Atlas Linguístico do Brasil (ALiB).

No registo dos aspetos inerentes aos referidos usos, por meio da tabulação e da exposição cartográfica das variantes lexicais, empregou-se o método geolinguístico, com o registo da frequência, por questão e por campo semântico. Assim, as etapas para a realização do estudo proposto consistem, primeiramente, na delimitação e na caracterização dos locais de estudo, seguido da elaboração do questionário, seleção e caracterização dos sujeitos e da realização das entrevistas. De acordo com o protocolo estabelecido, procedeu-se à análise semântico-lexical, de cariz quantitativo, com base nas lexias de maior frequência no corpus, por campo semântico e por questão. Tais procedimentos metodológicos permitiram a realização do registo das variações diatópicas, que se processam a nível semântico-lexical, de duas variedades linguísticas: a brasileira e a portuguesa, mais especificamente, a cuiabana e a covilhanense, respetivamente, num recorte sincrónico.

O processo de seleção dos pontos de inquérito, simplesmente denominados de pontos linguísticos, leva em consideração alguns pré-requisitos necessários para a aplicação do método de análise proposto por Brandão (I99I: 8I). Como instrumento para o levantamento e registo de dados relativos aos aspetos sociais, geo-económicos e históricos de cada ponto linguístico pes- 
quisado, foi utilizada a Ficha da Localidade (anexo I), elaborada com base na ficha proposta pelo Projeto ALiB, cujo objetivo é, de forma sucinta, conhecer cada ponto linguístico.

O presente estudo apenas considerará, sob o ponto de vista analítico, a importância das variantes lexicais informadas pelos inquiridos, confrontando-as com os principais estudos dialetológicos e descrevendo-se a norma lexical, documentando-se, igualmente, a riqueza sinonímica de cada localidade estudada e estabelecendo-se comparações, tanto entre si, quanto em relação ao conceito proposto pelo QSL. A análise quantitativa e qualitativa, relativa ao campo semântico, faz alusões aos regionalismos, apontando os casos relacionados com palavras cujo significado remete para conteúdo semântico distinto, vocábulos diferentes para o mesmo significante, lexias coincidentes e divergentes, bem como a ocorrência de palavras polissémicas e arcaísmos, em ambos os corpora. Tomar-se-á, ainda, em consideração as características extralinguísticas selecionadas e a sua relação com algumas mudanças em curso, nos dois pontos geográficos.

\section{Enquadramento metodológico do estudo}

\subsection{Caracterização dos pontos linguísticos}

A cidade de Cuiabá é a capital do estado de Mato Grosso e está localizada nas coordenadas $15^{\circ} 35^{\prime} 46^{\prime \prime}$ de latitude Sul e $5^{\circ} 05^{\prime} 48^{\prime \prime}$ de longitude Oeste. De acordo com dados do IBGE (20I4), Cuiabá apresentava, em 20I3, uma população estimada de 569,8 mil habitantes. A área do município corresponde a $3.495,4 \mathrm{~km}^{2}$, o que reporta a uma densidade populacional de $\mathrm{I}_{3}$ habitantes $/ \mathrm{km} 2$. Com altitude média de I25 metros, possui um clima tropical quente e duas estações definidas: um período chuvoso e um outro com baixa pluviosidade.

Quanto ao outro ponto linguístico, o Concelho da Covilhã localiza-se ao Norte do distrito de Castelo Branco, nas coordenadas $40^{\circ} 28^{\prime} 26^{\prime \prime}$ de latitude e - $75^{\circ} 03^{\prime} 26^{\prime \prime}$ de longitude Oeste. De acordo com os dados da Câmara Municipal (20I4), a Covilhã apresentava, em 20I3, uma população estimada em 53,5 mil habitantes. A área do município corresponde a $555,6 \mathrm{~km}^{2}$, o que reporta a uma densidade populacional de 96,2 habitantes $/ \mathrm{km} 2$. Ao considerarmos as contribuições de Cunha e Cintra (200I) e de Cintra (I995), verifica-se que a variedade do falar do Concelho da Covilhã, normalmente designado de "dialeto beirão", ora se integra num dialeto descrito como intermédio entre um Norte arcaizante e um Sul inovador, ora se encontra isolado, devido às 
características diferenciadoras e invulgares, especialmente, no aspeto fonético, dentro do território linguístico continental.

\subsection{Constituição do corpus linguístico}

Para a constituição do corpus linguístico, optou-se pela aplicação do QSL, baseado no Atlas Linguístico do Brasil (ALiB) e complementado por alguns conceitos do Atlas Linguístico-Etnográfico de Portugal e da Galiza (ALEPG). O QSL permitiu homogeneizar os dados linguísticos de vários informantes para posterior análise comparativa e, apesar do QSL, em muitos casos, ocultar particularidades dos falares locais, a sua validade sustenta-se no facto de ser um instrumento de orientação das informações. Também, como recurso para a obtenção de dados, foram utilizadas gravuras de alguns objetos, principalmente daqueles característicos da vida e das atividades rurais.

As entrevistas ocorreram entre os meses de setembro a dezembro de 2012 , no Concelho da Covilhã, onde foram auscultados 50 informantes e, em Cuiabá, o questionário foi, igualmente, aplicado a 50 habitantes, no período compreendido entre julho a setembro de 2013 , perfazendo um total de Ioo entrevistas, as quais decorreram nos mais variados ambientes e sempre precedidas de uma conversa introdutória de orientação sobre a atividade proposta. As variantes lexicais anotadas foram compiladas num banco de dados semântico-lexical no Microsoft Excel e organizadas por campo semântico, mantendo a estrutura da recolha dos dados linguísticos. Em várias circunstâncias, registaram-se duas ou mais expressões lexicais para designar o mesmo conceito, optando-se pela primeira para a constituição do corpus a ser analisado, por julgarmos que se trata da designação mais usual pelo entrevistado e a que particulariza o falar local. A título de exemplo, podem-se referir as respostas à questão II3, forreta/fuinha/agarrado, registadas na Covilhã e pão-duro/sovina/cainha, registadas em Cuiabá. Nestes casos, selecionaram-se as variantes lexicais forreta e pão-duro, ou seja, para a constituição do corpus foram excluídas as demais respostas dos sujeitos, pelo volume de dados a serem considerados, o que não inviabiliza a possibilidade desse conjunto de dados linguísticos excluídos serem trabalhados posteriormente.

A base desta análise segue as inferências destacadas por Muller (I968), que permite empregar noções de frequências absoluta e relativa, no intuito de estabelecer uma norma referente aos aspetos semântico-lexicais de uma determinada comunidade linguística. A percentagem foi calculada com base na 
frequência absoluta ou no número total de 50 sujeitos entrevistados em cada ponto linguístico. Estes correspondem a I००\% no corpus ou a uma relação percentual que sempre corresponderá ao dobro da frequência. Acresce que todas as variantes são consideradas para efetivo cálculo das percentagens nos grupos de cada variável extralinguística. No entanto, são analisadas apenas as variantes que indicam alguma tendência, em pelo menos um dos locais de estudo, por meio de exposições gráficas, com base na sequência proposta pelo QSL. Todavia, todas as variantes de maior frequência tiveram as suas percentagens devidamente consideradas e encontram-se ilustradas na tabela 2 .

A análise analítica levada a cabo neste ensaio contempla, apenas, o campo semântico "Convívio e Comportamento Social" (questões III a I23, cf. anexo III).

\subsection{Caracterização dos informantes}

Da mesma forma como fora feito para a obtenção dos dados relativos às localidades, utilizou-se a Ficha do Sujeito (cf. anexo II) ${ }^{2}$ com a finalidade de registar informações que caracterizem cada entrevistado e, ao mesmo tempo, permitam traçar o seu perfil, devidamente previsto para o estudo em questão, bem como validar a aplicabilidade da pesquisa. Os informantes não foram identificados em nenhuma situação no decorrer do trabalho, tendo em vista os princípios éticos da investigação científica, além do facto de a variante informada constituir o único interesse para o tratamento dos resultados esperados.

A distribuição quanto à variável faixa etária aponta que ıo \% dos entrevistados na Covilhã possuíam, até à data da entrevista, menos de 35 anos. Outros $64 \%$ encaixavam-se na faixa etária entre 36 a 55 anos, seguido de $26 \%$ com 56 anos ou mais. Para Cuiabá, $22 \%$ possuem menos de 35 anos, $44 \%$ encontram-se com a idade entre 36 e 55 anos e $34 \%$ possuem 56 anos ou mais. Quanto à variável género, houve certa equidade. No que diz respeito à variável escolaridade, a grande maioria dos informantes entrevistados, em ambos os pontos linguísticos, não possui ensino superior.

Acresce que a maioria dos entrevistados é natural e residente da localidade em estudo e, dos 50 informantes cuiabanos, 66 \% são considerados nativos. No ponto linguístico Covilhã, de entre os 50 informantes observados, $78 \%$

\footnotetext{
${ }^{2}$ A ficha do sujeito foi elaborada com base na ficha proposta pelo Atlas Linguístico do Brasil (ALiB), descrita no anexo II.
} 
são considerados nativos, por terem nascido e, ainda, residirem no local. Outros $4 \%$, apesar de residirem na Covilhã, nasceram na região, ou nos municípios ao redor e, somente, I8 \% são nativos de outras regiões ou países. Desta forma, quando da referência nas cartas lexicais das questões, a nomenclatura infere que se trata das variantes informadas pelos $66 \%$ dos cuiabanos e $78 \%$ dos covilhanenses.

Assim:

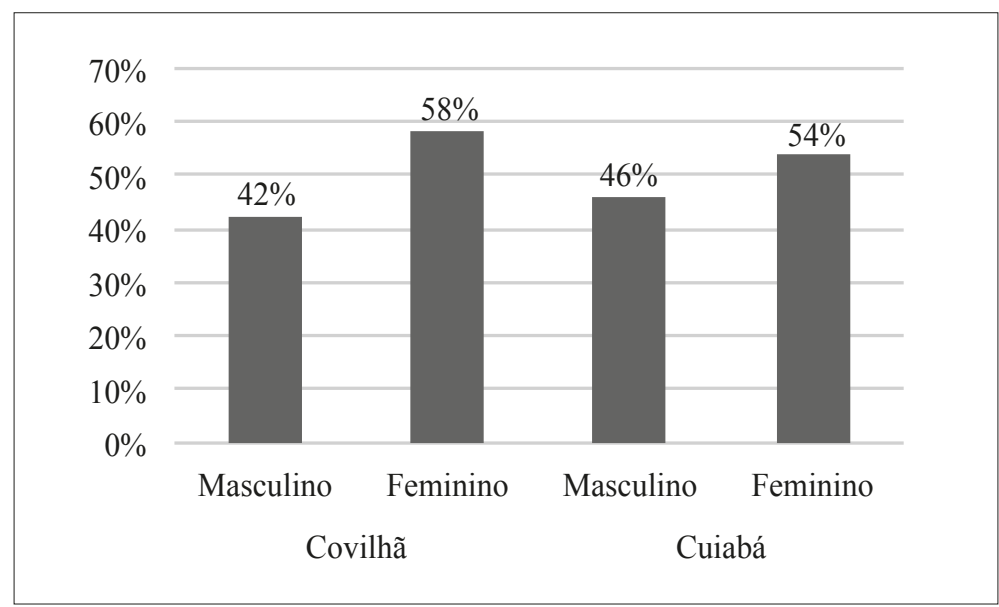

Gráfico I. Género

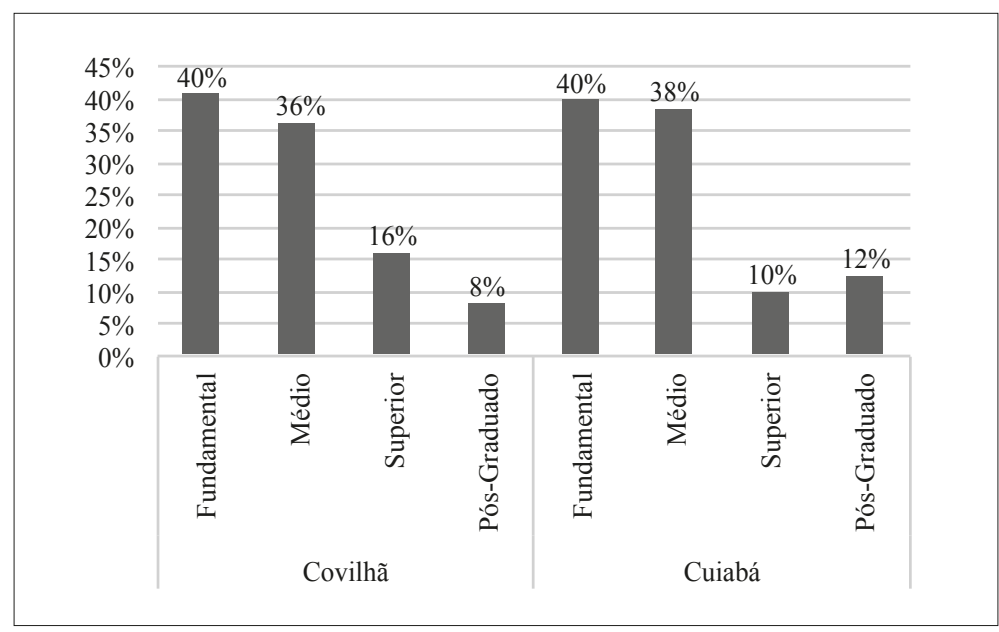

Gráfico 2. Escolaridade 


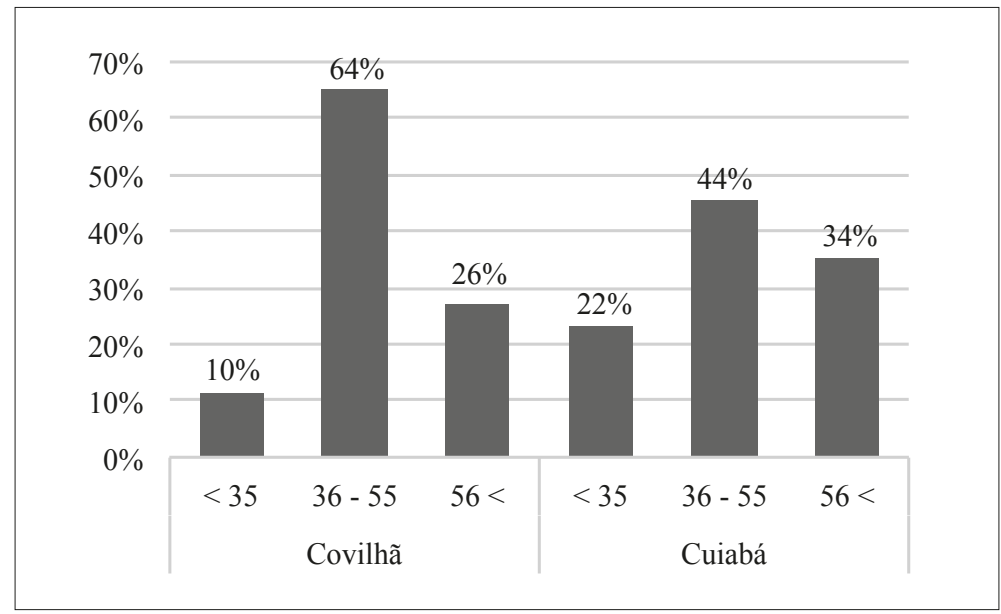

Gráfico 3. Faixa etária

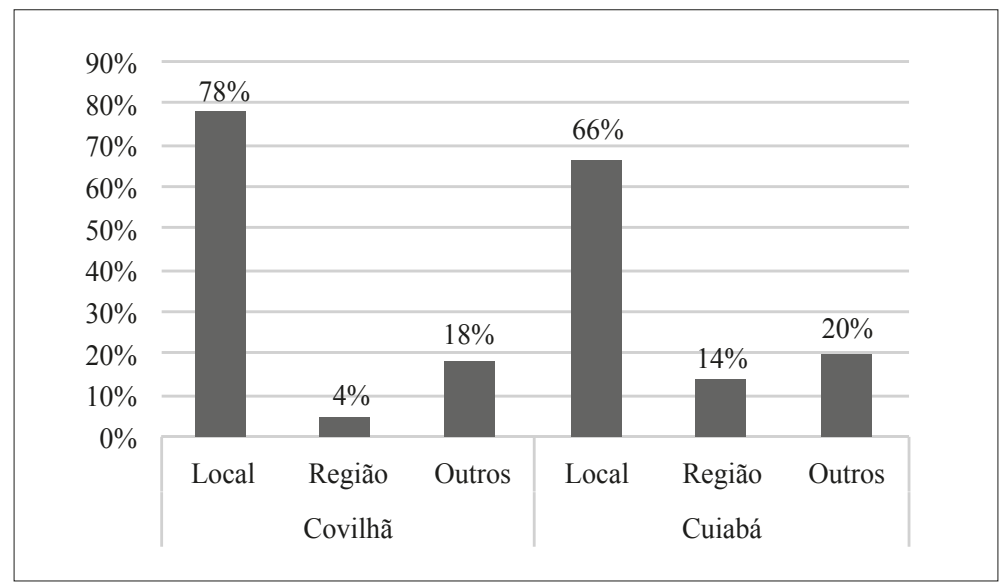

Gráfico 4. Naturalidade

\section{Análise das variedades lexicais do campo semântico "Convívio e Comportamento Social"}

As questões numeradas de III a I23, propostas pelo QSL, são relativas ao campo semântico “Convívio e Comportamento Social” e compõem a tabela I do corpus em análise: 


\begin{tabular}{|c|c|c|c|c|c|c|c|}
\hline \multirow[b]{3}{*}{ 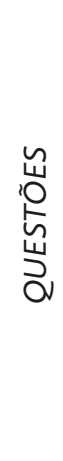 } & \multirow[b]{3}{*}{ 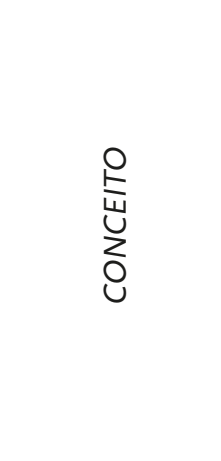 } & \multicolumn{6}{|c|}{ PONTOS LINGUÍSTICOS } \\
\hline & & \multicolumn{3}{|c|}{ CUIABÁ - BR } & \multicolumn{3}{|c|}{ COVILH $\tilde{A}-P T$} \\
\hline & & 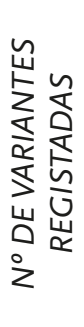 & 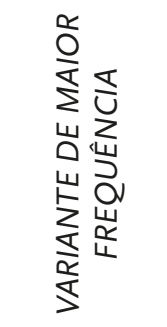 & $\%$ & 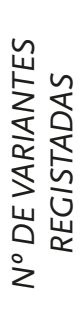 & 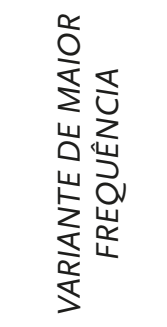 & $\%$ \\
\hline 111 & Pessoa tagarela & 11 & Tagarela & $50 \%$ & $\mathrm{O} 4$ & Fala barato & $40 \%$ \\
\hline 112 & $\begin{array}{l}\text { Pess. pouco } \\
\text { inteligente }\end{array}$ & 05 & Rude (o) & $62 \%$ & 09 & Burro & $62 \%$ \\
\hline 113 & Pessoa sovina & 07 & Pão-duro & $36 \%$ & 06 & Forreta & $72 \%$ \\
\hline 114 & Mau pagador & 06 & $\begin{array}{l}\text { Mau pa- } \\
\text { gador }\end{array}$ & $42 \%$ & 01 & Caloteiro & $100 \%$ \\
\hline 115 & $\begin{array}{l}\text { Marido } \\
\text { enganado }\end{array}$ & 03 & Corno & $44 \%$ & 04 & Cornudo & $48 \%$ \\
\hline 116 & Prostituta & 06 & Prostituta & $64 \%$ & $\mathrm{O} 2$ & Prostituta & $80 \%$ \\
\hline 117 & Xará & $\mathrm{O} 2$ & Xará & $92 \%$ & $\mathrm{O} 2$ & Homônimo & $72 \%$ \\
\hline 118 & Bêbado & 08 & Bêbado & $50 \%$ & 03 & Bêbado & $96 \%$ \\
\hline 119 & Toco do cigarro & O4 & Bituca & $70 \%$ & $\mathrm{O} 2$ & Beata & $56 \%$ \\
\hline 120 & Açougueiro & 01 & Açougueiro & $100 \%$ & $\mathrm{O} 4$ & Carniceiro & $42 \%$ \\
\hline 121 & Cidade & $\mathrm{O} 2$ & Cidade & $84 \%$ & 01 & Cidade & $100 \%$ \\
\hline 122 & Vila & 05 & Vila & $44 \%$ & 01 & Vila & $100 \%$ \\
\hline 123 & Aldeia & 04 & Corrutela & $72 \%$ & 01 & Aldeia & $100 \%$ \\
\hline
\end{tabular}

Tabela I. Campo semântico “Convívio e Comportamento Social”

Nesta tabela, apresentam-se, então, o número de variantes registadas, as lexias de maior frequência e a efetiva percentagem, respetivamente, nos dois pontos linguísticos. A carta lexical do campo semântico em estudo expõe 
todas as variantes obtidas junto aos informantes brasileiros e portugueses, como esclarece a figura s:

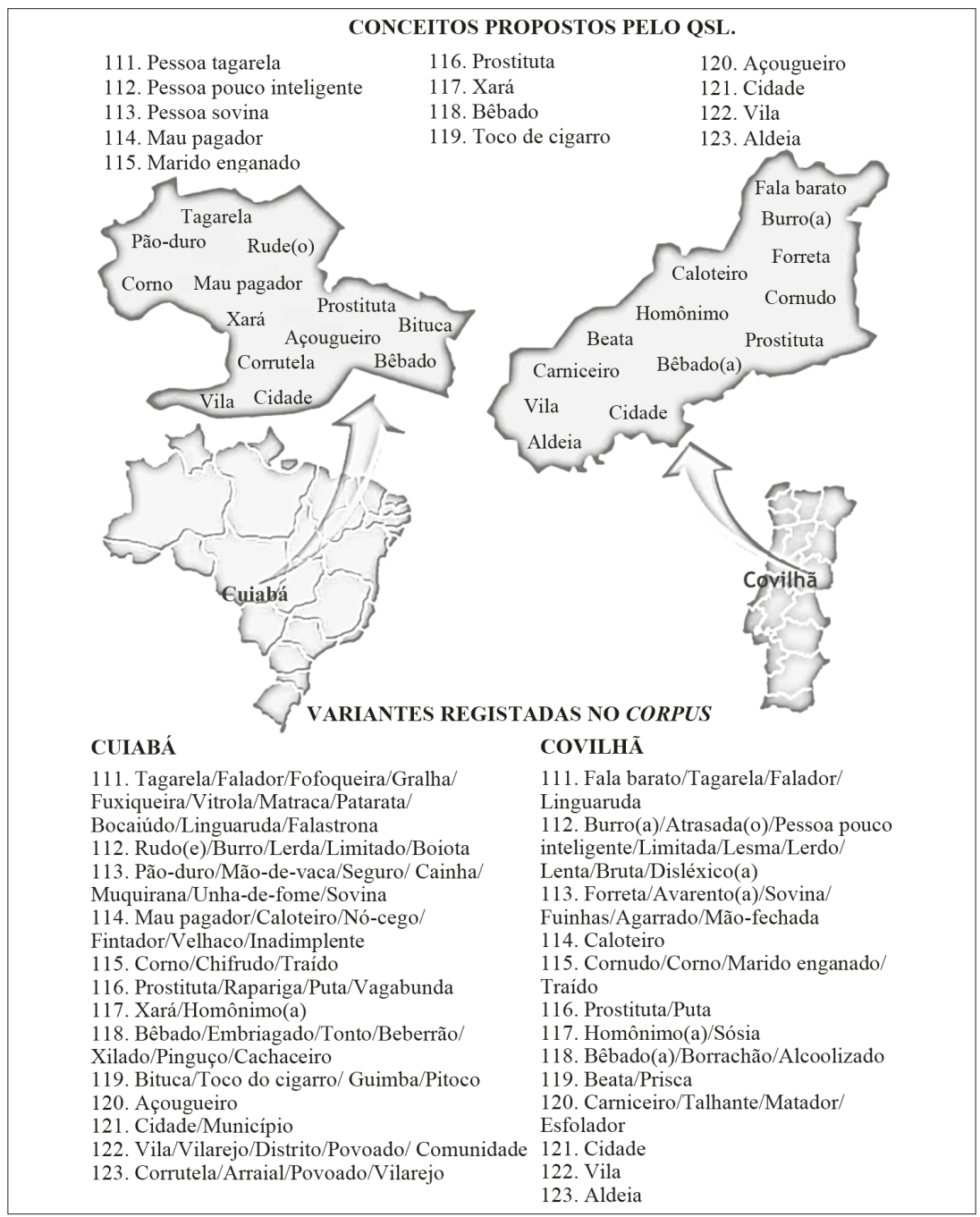

Figura I. Carta lexical do campo semântico "Convívio e Comportamento Social”

Ao cruzarmos as variantes registadas com as variáveis extralinguísticas (género, faixa etária, escolaridade e naturalidade), obtemos os seguintes dados: 


\begin{tabular}{|c|c|c|c|c|c|c|c|c|c|c|c|c|}
\hline \multicolumn{13}{|c|}{ CAMPO SEMÂNTICO: "CONVÍVIO E COMPORTAMENTO SOCIAL" } \\
\hline \multirow{2}{*}{$\mathbf{N}^{\circ}$} & \multirow{2}{*}{ CUIABÁ } & \multicolumn{2}{|c|}{ Género } & \multicolumn{3}{|c|}{ Faixa Etária } & \multicolumn{3}{|c|}{ Escolaridade } & \multicolumn{3}{|c|}{ Naturalidade } \\
\hline & & MAS & FEM & $<35$ & $36-55$ & $>56$ & FUN & MED & SUP & LOC & REG & OUT \\
\hline 111 & Tagarela & $\%$ & & $82 \%$ & $.1 \%$ & $.1 \%$ & $40 \%$ & $53 \%$ & $64 \%$ & $55 \%$ & $14 \%$ & $60 \%$ \\
\hline 112 & Rude (o) & $\%$ & $56 \%$ & $36 \%$ & $4 \%$ & $76 \%$ & $75 \%$ & $68 \%$ & $27 \%$ & 70 & $57 \%$ & $40 \%$ \\
\hline 113 & Pão-duro & $39 \%$ & 3 & $18 \%$ & $36 \%$ & $47 \%$ & $45 \%$ & $\%$ & $18 \%$ & $39 \%$ & $29 \%$ & $30 \%$ \\
\hline 114 & $\begin{array}{l}\text { Mau } \\
\text { pagador }\end{array}$ & $48 \%$ & $37 \%$ & $27 \%$ & $36 \%$ & $59 \%$ & $55 \%$ & $32 \%$ & $36 \%$ & $39 \%$ & $43 \%$ & $50 \%$ \\
\hline 115 & Corno & $3 \%$ & $44 \%$ & $64 \%$ & $41 \%$ & $35 \%$ & $40 \%$ & $47 \%$ & $45 \%$ & 3910 & $13 \%$ & $60 \%$ \\
\hline 116 & Prostit & $65 \%$ & $63 \%$ & $91 \%$ & $50 \%$ & $65 \%$ & $80 \%$ & $58 \%$ & $45 \%$ & $58 \%$ & $71 \%$ & $80 \%$ \\
\hline 117 & Xará & $87 \%$ & $96 \%$ & $100 \%$ & $86 \%$ & $94 \%$ & $100 \%$ & $95 \%$ & $73 \%$ & $8 \%$ & $100 \%$ & $100 \%$ \\
\hline 118 & Bêbado & $48 \%$ & $52 \%$ & $64 \%$ & $45 \%$ & $47 \%$ & $60 \%$ & $32 \%$ & $64 \%$ & $42 \%$ & $57 \%$ & $70 \%$ \\
\hline 119 & Bituca & (2) & $74 \%$ & $64 \%$ & 1570 & $71 \%$ & 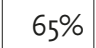 & $79 \%$ & $64 \%$ & & $86 \%$ & $100 \%$ \\
\hline 120 & Açoug & $100 \%$ & $100 \%$ & $0 \%$ & $100 \%$ & $100 \%$ & $100 \%$ & $100 \%$ & $100 \%$ & $100 \%$ & $100 \%$ & $100 \%$ \\
\hline 121 & Cidade & $87 \%$ & $81 \%$ & $100 \%$ & $77 \%$ & $82 \%$ & $75 \%$ & $84 \%$ & $100 \%$ & $88 \%$ & $86 \%$ & $70 \%$ \\
\hline 122 & Vila & 3,0 & $44 \%$ & $55 \%$ & $45 \%$ & $35 \%$ & $50 \%$ & $\%$ & $36 \%$ & $2 / 0$ & $43 \%$ & $40 \%$ \\
\hline 123 & Corrutela & $74 \%$ & $70 \%$ & $82 \%$ & $64 \%$ & $76 \%$ & $80 \%$ & $68 \%$ & $64 \%$ & $64 \%$ & $100 \%$ & $80 \%$ \\
\hline $\mathbf{N}^{\circ}$ & OVILHÃ & MAS & FEM & $<35$ & $36-55$ & $>56$ & FUN & MED & SUP & LOC & REG & OUT \\
\hline 111 & Fala b & 0 & $34 \%$ & $40 \%$ & $\%$ & $46 \%$ & $30 \%$ & $\%$ & $33 \%$ & 70 & $\%$ & $44 \%$ \\
\hline 112 & Burro (a) & 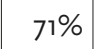 & טינד & $40 \%$ & 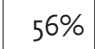 & 0 & $65 \%$ & $67 \%$ & $50 \%$ & $64 \%$ & $100 \%$ & $44 \%$ \\
\hline 113 & Forreta & $62 \%$ & $79 \%$ & $80 \%$ & $69 \%$ & $77 \%$ & $80 \%$ & $61 \%$ & $75 \%$ & $72 \%$ & $100 \%$ & $67 \%$ \\
\hline 114 & Caloteiro & $100 \%$ & $100 \%$ & $100 \%$ & $100 \%$ & $100 \%$ & $100 \%$ & $100 \%$ & $100 \%$ & $100 \%$ & $100 \%$ & $100 \%$ \\
\hline 115 & c & $38 \%$ & 0 & 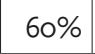 & $53 \%$ & 10 & 10 & $\%$ & $\%$ & $49 \%$ & $\%$ & $6 \%$ \\
\hline 116 & Prostituta & $86 \%$ & $76 \%$ & $80 \%$ & $78 \%$ & $85 \%$ & $80 \%$ & $89 \%$ & $67 \%$ & $85 \%$ & $50 \%$ & $67 \%$ \\
\hline 117 & $\begin{array}{l}\text { Homônimo } \\
\text { (a) }\end{array}$ & $86 \%$ & $62 \%$ & $100 \%$ & $75 \%$ & $54 \%$ & $60 \%$ & $83 \%$ & $75 \%$ & $72 \%$ & $100 \%$ & $67 \%$ \\
\hline 118 & Bêbado & $95 \%$ & $97 \%$ & $100 \%$ & $97 \%$ & $92 \%$ & $90 \%$ & $100 \%$ & $100 \%$ & $95 \%$ & $100 \%$ & $100 \%$ \\
\hline 119 & Beata & $52 \%$ & 5 & $\%$ & $63 \%$ & $31 \%$ & $40 \%$ & $\%$ & $\%$ & 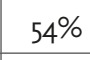 & $\%$ & $78 \%$ \\
\hline 120 & Carnic & $\%$ & $\%$ & $20 \%$ & $4 \%$ & $46 \%$ & $50 \%$ & $22 \%$ & $58 \%$ & $41 \%$ & $50 \%$ & $44 \%$ \\
\hline 121 & Cidade & $100 \%$ & $100 \%$ & $100 \%$ & $100 \%$ & $100 \%$ & $100 \%$ & $100 \%$ & $100 \%$ & $100 \%$ & $100 \%$ & $100 \%$ \\
\hline 122 & Vila & $100 \%$ & $100 \%$ & $100 \%$ & $100 \%$ & $100 \%$ & $100 \%$ & $100 \%$ & $100 \%$ & $100 \%$ & $100 \%$ & $100 \%$ \\
\hline 123 & Aldeia & $100 \%$ & $100 \%$ & $100 \%$ & $100 \%$ & $100 \%$ & $100 \%$ & $100 \%$ & $100 \%$ & $100 \%$ & $100 \%$ & $100 \%$ \\
\hline
\end{tabular}

Tabela 2. Cruzamento das variantes com as variáveis extralinguísticas 
A partir da análise da tabela I, verifica-se que as lexias simples caloteiro, cidade, vila e aldeia, relativas às questões II4, I2I, I22 e I23, respetivamente, são consideradas as respostas de maior frequência identificadas no campo semântico supracitado, inscritas com a percentagem de Ioo \%, no ponto linguístico Covilhã, enquanto que a lexia de maior frequência registada no ponto linguístico Cuiabá fora açougueiro (I00\%), como resposta à questão I20, a qual coincide com a variante lexical proposta pelo QSL.

Na carta lexical do campo semântico "Convívio e Comportamento Social" (figura I), registam-se as lexias que se empregam em Cuiabá e na Covilhã para designar "a pessoa que fala demais". Essa noção exprime-se, no primeiro ponto linguístico, por meio de onze itens lexicais: tagarela (50\%), variante de maior frequência e que corresponde ao conceito proposto pelo QSL, falador (16 \%), fofoqueira (8\%), gralha (8\%), matraca (4\%), pararaca (4\%), fuxiqueira (2 \%), vitrola (2\%), bocaiúdo (2\%), linguaruda (2\%) e falastrona (2\%). No ponto linguístico Covilhã, obtiveram-se as seguintes designações: fala-barato (40\%), variante lexical de maior frequência, tagarela (30\%), falador (28\%) e linguaruda ( $2 \%)$. Destas, três são coincidentes nos dois corpora. Constata-se, portanto, o registo de um expressivo número de significantes para o mesmo significado, ou seja, a riqueza sinonímica da língua portuguesa. Também, a ocorrência das lexias tagarela e fala-barato foram as variantes lexicais de maior frequência entre os informantes nativos de Cuiabá e da Covilhã, respetivamente.

Houaiss e Villar (2010) indicam que a lexia fofoqueira, de uso informal, é um regionalismo do Brasil e designa "... aquela que faz fofoca, que se intromete em assuntos alheios". De forma análoga, fuxiqueira também consta como regionalismo do Brasil, usado informalmente para designar "... o que fuxica, faz intrigas; fuxiquento". Em relação à gralha, Houaiss e Villar (20I0) assinalam a ocorrência de uma derivação por analogia: "pessoa que fala muito, lembrando o grasnar das gralhas; tagarela”. Houaiss e Villar (20I0) registam a lexia vitrola, proveniente do inglês Victrola, como regionalismo do Brasil, empregada, informalmente, na aceção de "pessoa que fala muito; tagarela". É também, normalmente, utilizado para designar "toca-discos". Relativamente à lexia pararaca que, segundo Nascentes, citado por Houaiss e Villar (2010), provém do tupi pa'ra 'mar', ra desin. e 'aka 'chifres', em distribuição de adjetivo, significa "que faz ou é dado a fazer barulho ou a falar muito: barulhento, tagarela" e, em distribuição substantiva, designa o "local, nos rios, onde a água passa agitada e barulhenta, removendo as pedras", configurando-se, como regionalismo dos estados de Minas Gerais, São Paulo e Goiás, outro fator que evidencia a influência da língua indígena na constituição do falar cuiabano. 
O Dicionário da Língua Portuguesa da Porto Editora assinala que a lexia complexa fala-barato, de caráter depreciativo, designa a "pessoa que fala muito e frequentemente a despropósito; palrador irresponsável". De acordo com a pesquisa realizada no TLPGP, a lexia fala-barato está documentada em trabalhos anteriores sobre o léxico do PE como, por exemplo, em Pereira (I970: 340), o qual remete à variante bate-fuolha, que significa a "pessoa que fala e mente muito" e, cita como sinónimos, "fala-barato, faroleiro, lareadeiro e tabaréu". Ainda se documenta a variante fala-barata, cujo significado remete à "mulher que fala muito", em CarvalhoA (I970: 526), ambas associadas ao campo semântico "Ser Humano (aspetos físicos, psíquicos e comportamentais)".

A carta lexical do campo semântico "Convívio e Comportamento Social" (figura I) indica as variantes léxicas empregadas em Cuiabá e Covilhã para designar "a pessoa que tem dificuldade para aprender". Essa noção manifesta-se, no primeiro ponto linguístico, por meio de cinco itens lexicais: rude/o $(62 \%)$, variante de maior frequência, burro (30\%), lerda (4\%), limitado ( $2 \%$ ) e boiota ( $2 \%$ ). No ponto linguístico Covilhã, obtiveram-se as lexias burro/a (62 \%), variante lexical de maior frequência, atrasado/a (I2 \%), pessoa pouco inteligente (го \%), limitada (4\%), disléxico/a (4\%), lesma (2\%), lerdo (2\%), lenta (2\%) e bruta (2\%). As variantes lexicais de maior frequência identificadas nos dois corpora são distintas relativamente ao conceito proposto pelo QSL. As variantes léxicas rude/o e burro/a foram as de maior frequência entre os cuiabanos e os informantes nativos do Concelho da Covilhã, respetivamente, e não indicam particularidades locais. Em Houaiss e Villar (20I0), encontra-se, no verbete rudo, datado do séc. XIII, a informação de ser uma forma linguística pouco usada, a qual designa o "m.q. rude". Houaiss e Villar (20I0) registam a lexia rude, em distribuição adjetiva, com dez aceções, destacadas como de uso geral, sem atribuição de uso específico no PE e no PB: "não cultivado; agreste, inculto", "que apresenta asperezas; áspero, rugoso", "desagradável, duro, insensível”, "áspero no trato; grosseiro, incivil, indelicado", "falto de inteligência, de instrução, de sensibilidade; ignorante, boçal, estúpido", "desprovido de beleza, de leveza; tosco, pesado". Apesar de não ter sido identificada na Covilhã a lexia rude, em distribuição de adjetivo e aceção de "pouco inteligente; estúpido", encontra-se documentada em trabalhos sobre o léxico do PE, conforme pesquisa realizada no TL$P G P$, em BaptistaF (I970: 665). Também se regista a variante lexical ruda, em distribuição substantiva, para designar o indivíduo "pouco esperto" em Amorim (I97I: 286), ambas anexadas ao campo semântico "Ser Humano (aspetos físicos, psíquicos e comportamentais)". 
De acordo com a pesquisa realizada no TLPGP, a variante léxica burro é indicada para designar: "armação de madeira sobre a qual apoiam a lenha para melhor a serrar" em BaptistaF (I970: 565), associada ao campo semântico "Madeira e Borracha"; "Jogo de Cartas" (Idem), porém anexa ao campo semântico "Ser Humano (aspetos espirituais)"; "nevoeiro” em Braga (I971: 3i6), "nevoeiro que se forma na serra, sinal de chuva" em Fernandes (I965: 24I), associada ao campo semântico "Meteorologia"; "instrumento utilizado para tirar água” em CarvalhoA (I970: 48I); "engenho para tirar água dos poços, também conhecido por picota, cegonha e que se compõe de três partes essenciais: espeque, rabadão, vara" em Moura (I960: I7I) - campo semântico "Rego e Fontes"; "burro; banco de três pés" em Delgado (I970: 36I), anexo ao campo semântico "Enxoval e Vida Doméstica"; "nome vulgar de um mamífero perissodáctilo, da família dos Equídeos" em Alves (I993: 202), pertencente ao campo semântico "Gado Equino". Houaiss e Villar (20I0) inscrevem o item lexical burro como um caso de "derivação: sentido figurado", empregado para designar "...aquele que é falto de inteligência; estúpido, tolo", atribuindo-lhe uma conotação pejorativa.

Também se registam as lexias pão-duro e forreta como as variantes de maior frequência empregadas pelos informantes nativos de Cuiabá e da Covilhã. Estas lexias, distintas ao conceito proposto pelo QSL, foram indicadas com $36 \%$ e $72 \%$, respetivamente, conforme tabela I. A carta lexical do campo semântico "Convívio e Comportamento Social” também regista os termos linguísticos: mão-de-vaca (20\%), seguro (I6\%), cainha (I4\%), muquirana (6\%), unha-de-fome (4\%) e sovina (4\%) em Cuiabá; avarento/a (I8 \%), sovina ( $4 \%)$, fuinhas $(2 \%)$, agarrado ( $2 \%)$ e mão-fechada $(2 \%)$ na Covilhã. Constata-se uma diferenciação lexical entre os pontos linguísticos, visto que foram obtidas i2 lexias distintas e apenas uma coincidente (sovina) para designar o mesmo referente. Houaiss e Villar (20I0) inscrevem a lexia complexa pão-duro, como regionalismo do Brasil, usada, informalmente, com o mesmo significado de avarento: "que ou aquele que é obcecado por adquirir e acumular dinheiro; sovina”. Quanto ao vocábulo forreta, além de designar "indivíduo avarento” em Dias (I982: 456), também está documentado na aceção de "utensílio de ferro para tirar as boroas do forno" em OliveiraR (I948: II2), associado ao campo semântico "Ferramenta e Maquinaria". A lexia sovina integra o léxico do PE, em distribuição de adjetivo e aceção de "pessoa agarrada" em Fernandes (1965: 309) e, em distribuição substantiva, na aceção de "pau aguçado com que picam os animais" em Fernandes (i965: 309), anexa ao campo semântico "Gado". 
A figura I, relativa à carta lexical do campo semântico "Convívio e Comportamento Social”, regista as lexias que se empregam em Cuiabá e na Covilhã para denominar "o indivíduo que não paga as suas contas". Essa noção manifesta-se, no primeiro ponto linguístico, por meio de seis itens lexicais: mau pagador (42\%), variante de maior frequência e correspondente ao conceito proposto pelo QSL, caloteiro (36\%), nó-cego (1о \%), fintador (8\%), velhaco (2\%) e inadimplente ( $2 \%)$. No ponto linguístico Covilhã, obteve-se a denominação caloteiro, inscrita com Ioo \%, que, aliás, coincide nos dois corpora. Esta lexia também integra o léxico do PE na aceção de "comilão" em CarvalhoS (I974: 443), associada ao campo semântico "Ser Humano (aspetos físicos, psíquicos e comportamentais)", conforme pesquisa realizada no TLPGP. As variantes lexicais de maior frequência mantiveram-se entre os informantes nativos e não indicam particularidades locais.

A carta lexical do campo semântico "Convívio e Comportamento Social" regista as lexias corno (44\%), variante de maior frequência, chifrudo (40 \%) e traído (I6 \%) no ponto linguístico brasileiro; cornudo (48\%), variante de maior frequência, corno (32\%), traído (I4 \%) e marido enganado (6\%), que corresponde ao conceito proposto pelo QSL, no ponto linguístico português, como respostas à questão II5. Em complemento, regista-se a ocorrência dos vocábulos chifrudo e cornudo, como as variantes lexicais de maior frequência entre os informantes nativos de Cuiabá e da Covilhã, respetivamente. De acordo com Houaiss e Villar (20I0), o termo linguístico chifrudo, de uso informal, configura-se como um regionalismo do Brasil e designa "corno" ('cônjuge enganado'). O vocábulo cornudo, mais representativo do falar da Covilhã, está lexicalizado em Houaiss e Villar (20IO) como um caso de "derivação: sentido figurado", usado de forma pejorativa para se referir ao "homem traído pela mulher".

Conforme pesquisa realizada no TLPGP, o vocábulo corno está documentado em trabalhos anteriores sobre o léxico do PB como, por exemplo, no Atlas Linguístico da Paraíba (ALPB: I20) para designar "o marido enganado pela mulher", associado ao campo semântico "Ser Humano (aspetos sociais)". Este vocábulo integra o léxico do PE em CarvalhoA (I970: 502) e Delgado (I970: 347) com a aceção proposta acima e, ainda, com a aceção de "chifre" em CarvalhoA (I970: 502) e Delgado (I970: 335). Dessa forma, o vocábulo corno apresenta mobilidade, pois transita, reciprocamente, de um campo semântico para outro, isto é, sai do campo semântico "Ser Humano" e se estende para o do "Animal", mais especificamente, o do "Gado".

A variante léxica prostituta, resposta à questão II6 do QSL, foi registada nos dois pontos linguísticos como a variante de maior frequência, inclusive 
entre os informantes nativos de Cuiabá e da Covilhã, com $64 \%$ e $80 \%$, respetivamente, conforme a tabela I. A carta lexical do campo semântico "Convívio e Comportamento Social" também inscreve as lexias: rapariga (I2 $\%)$, puta (I2\%), vagabunda (6\%), biscate (4\%) e piranha (2\%) no ponto linguístico Cuiabá e puta (20\%) no ponto linguístico Covilhã, para designar o mesmo referente.

Houaiss e Villar (20I0) indicam, na terceira aceção, que o item lexical rapariga é um regionalismo da Amazónia, cujo significado remete à "moça virgem; donzela". Ainda se configura como um regionalismo da região Nordeste e dos Estados de Minas Gerais e Goiás nas seguintes aceções: "mulher que vive da prostituição; meretriz, prostituta", "mulher que vive maritalmente com um homem; concubina”. De acordo com o Dicionário da Língua Portuguesa da Porto Editora, no Brasil, atribui-se à lexia rapariga uma conotação pejorativa quando empregada na aceção de "amante" e "prostituta". Também há registo deste termo linguístico, em Portugal, para designar "namorada" em Nunes (1965: I5I), conforme pesquisa realizada no TLPGP.

Houaiss e Villar (2010) assinalam que a lexia puta, em distribuição substantiva, assume um caráter disfémico na aceção de "prostituta". Também é empregada para, pejorativamente, se referir a "qualquer mulher lúbrica que se entregue à libertinagem" e, em distribuição de adjetivo, configura-se como regionalismo do Brasil, empregado como termo hiperbolizante, no sentido de 'enorme, fantástico, excelente, sensacional'. Ainda inscreve o item lexical piranha, proveniente do tupi pi'rãya, literalmente 'peixe com dente', como regionalismo do Brasil, usado pejorativamente para se referir a "mulher que mantém relações sexuais por dinheiro; prostituta, meretriz".

As variantes lexicais xará e homônimo, empregadas para designar "a pessoa que tem o nome idêntico ao de outra", foram registadas com a expressiva frequência de $92 \%$ e $72 \%$ em Cuiabá e na Covilhã, respetivamente, como pode ser observado na tabela I. No ponto linguístico Cuiabá, além da variante de maior frequência, xará, emprega-se a lexia homônimo/a (8\%), enquanto que no ponto linguístico Covilhã fora indicado o item lexical sósia $(8 \%)$ para o mesmo referente, como exposto na figura I. De entre os informantes portugueses, 20 \% afirmaram desconhecer o termo específico. Em relação aos informantes nativos, não houve distinção entre as variantes de maior frequência em ambos os pontos linguísticos.

Houaiss e Villar (20ı) indicam que o item lexical xará é um regionalismo do Brasil, cujo significado remete à "pessoa com nome de batismo idêntico ao de outra; xarapim, tocaio". Segundo Antônio Geraldo da Cunha, citado por 
Houaiss e Villar (2010), a lexia xará provém do tupi *xa'ra, de xe rera 'meu nome', o que evidencia a influência da língua indígena no falar cuiabano.

A variante léxica bêbado, resposta à questão II8 do QSL, foi registada nos dois pontos linguísticos como a variante de maior frequência, inclusive entre os informantes nativos de Cuiabá e da Covilhã, com $50 \%$ e $96 \%$, respetivamente, conforme ilustra a tabela I (anexo IV). A carta lexical do campo semântico "Convívio e Comportamento Social" também inscreve as designações: xilado (เо \%), pinguço (เо \%), cachaceiro (เо \%), beberrão (8\%), embriagado (6\%), tonto (4\%) e pau-d'água ( $2 \%$ ) no ponto linguístico Cuiabá; borrachão (2 \%) e alcoolizado ( $2 \%)$ no ponto linguístico Covilhã. Constata-se uma diferenciação lexical entre os pontos linguísticos, visto que foram obtidas nove lexias distintas e apenas uma coincidente, que correspondem ao mesmo significado.

Houaiss e Villar (20I0) registam a lexia composta pau-d'água, em distribuição substantiva, como regionalismo do Brasil, usada informalmente para designar "aquele que tem o hábito de embriagar-se; bêbedo, ébrio". De forma análoga, o vocábulo xilado, de origem obscura, também se configura como um regionalismo do Brasil, de uso informal, cujo significado remete ao indivíduo "intoxicado com bebida alcoólica; alcoolizado, bêbedo". Os referidos lexicógrafos indicam a lexia pinguço, derivada da palavra pinga 'bebida alcoólica, esp. aguardente de cana' + -uço, como regionalismo das regiões Nordeste e Sul do Brasil e do Estado de Minas Gerais, empregada para denominar “... aquele que se embriaga; bêbedo, cachaceiro".

A carta lexical do campo semântico "Convívio e Comportamento Social" (figura I) regista as lexias bituca (70 \%), toco do cigarro (24\%) guimba (4\%) e pitoco (2\%) no ponto linguístico brasileiro; beata (56\%) e prisca (44\%) no ponto linguístico português, como respostas à questão II9. Verifica-se, portanto, um contraste linguístico entre as áreas em estudo, visto que foram obtidos seis vocábulos diferentes para o mesmo significante. As lexias de maior frequência, bituca e beata, distintas e correspondentes ao conceito de "toco do cigarro" (proposto pelo QSL, cf. tabela I) mantêm-se, inclusive, entre os informantes nativos.

O termo linguístico prisca, em distribuição substantiva, configura-se como um regionalismo da região Sul do Brasil, usada informalmente, cujo significado remete ao verbete guimba: "a parte restante de um charuto, cigarro ou baseado já fumado”. Segundo Nei Lopes, citado por Houaiss e Villar (2010), "possivelmente, do quimbundo kima 'coisa', através da expressão kambundu ia kima 'pedaço'. Trata-se de outro facto que evidencia a influência das línguas africanas trazidas pelos escravos na formação sociocultural do povo cuiabano. 
Houaiss e Villar (2010) registam o termo linguístico bituca, cuja etimologia radica na "alteração de içabitu <tupi i’sa 'formiga' + ibi'tu 'vento, que voa, com asas para voar', como regionalismo do Brasil, usado na linguagem de delinquentes, para designar o "indivíduo que não paga as dívidas". Os referidos lexicógrafos não fazem referência à variante léxica bituca na aceção de "toco de cigarro", entretanto, o Dicionário da Língua Portuguesa da Porto Editora indica que o termo linguístico bituca, no Brasil, designa "beata, prisca". De acordo com a pesquisa realizada no TLPGP, a lexia beata encontra-se documentada em trabalhos anteriores sobre o léxico do PE na aceção de "papel em que se enrola o tabaco; mortalha" em Gouveia (I95I: I69) e "ponta do cigarro" em Paulino (I959: 302), por meio da variante fonética biata, ambas anexadas ao campo semântico "Tabaco".

Os vocábulos açougueiro e carniceiro foram registados como as variantes de maior frequência empregadas pelos informantes nativos de Cuiabá e da Covilhã, para denominar o "indivíduo que abate e esfola as reses nos matadouros". Estas variantes lexicais foram registadas com a percentagem de Io० $\%$ e $42 \%$, respetivamente, de entre a totalidade dos informantes, como pode ser observado na tabela I. A partir da figura I, relativa à carta lexical do campo semântico "Convívio e Comportamento Social", verifica-se que na Covilhã também se empregam para o conceito anteriormente mencionado os termos equivalentes: talhante (26\%), matador (26\%) e esfolador (2\%). Dentre os inquiridos portugueses, $4 \%$ alegaram desconhecer o termo específico.

A variante léxica cidade, resposta à questão I2I do QSL, foi registada noS dois pontos linguísticos como a variante de maior frequência, inclusive entre os informantes nativos de Cuiabá e da Covilhã, com a percentagem de 84 \% e ı०० \%, respetivamente. A carta lexical do campo semântico "Convívio e Comportamento Social” também inscreve a lexia município (I6 \%) em Cuiabá, para o mesmo referente.

Para designar a "povoação de categoria inferior a cidade e superior a aldeia”, o QSL propõe a lexia vila, registada no ponto linguístico Cuiabá com a percentagem de $44 \%$. Na Covilhã, essa percentagem eleva-se para Io० \% dos registos, conforme ilustra a tabela I. Para o mesmo referente, registam-se as seguintes variantes lexicais: vilarejo (26\%), distrito (I6\%), povoado (I2 \%) e comunidade (2 \%), no falar cuiabano. Em relação aos informantes nativos, não houve distinção entre as variantes de maior frequência em ambos os pontos linguísticos.

Os vocábulos corrutela e aldeia, referentes à questão I23, foram registados como as variantes léxicas de maior frequência empregadas pelos informantes 
nativos de Cuiabá e da Covilhã, respetivamente. Estas lexias foram registadas com $72 \%$ e $100 \%$, como pode ser observado na tabela I. A carta lexical do campo semântico "Convívio e Comportamento Social" também regista as lexias: povoado (I4 \%), arraial (io \%) e vilarejo (4\%), no ponto linguístico Cuiabá, para o mesmo referente.

Houaiss e Villar (20I0) registam a lexia corruptela com quatro aceções, três destacadas como de uso geral, sem atribuição de uso específico no PB ou no PE e uma com marcação de uso regional, isto é, como regionalismo de Goiás, com o significado de "reunião temporária de garimpeiros em aldeias, acampamentos". Os lexicógrafos assinalam que o vocábulo aldeia, na aceção de "povoação habitada apenas por índios; maloca, aldeamento" configura-se como regionalismo do Brasil.

\section{Considerações finais}

A análise quantitativa, que considerou as lexias de maior frequência, entre os pontos linguísticos investigados, independentemente do conceito proposto, revelou 4 (3I \%) ocorrências lexicais semelhantes entre duas variedades diatópicas, justamente aquelas que coincidem com o tema da questão proposto pelo ALiB. Por outro lado, 9 (69 \%) variantes são divergentes e, deste grupo, 4 (3I \%), além de divergirem entre as comunidades de fala, não contemplam o conceito sugerido e reafirmam as diferenças de realização de formas linguísticas entre falantes da língua portuguesa, neste caso, de áreas geográficas intercontinentais.

A metodologia utilizada permitiu, pois, identificar possíveis mudanças em curso, por meio da observação do comportamento de uso linguístico diferenciado dos falantes, estratificados em três faixas etárias: 25 a 35 anos; 36 a 55 anos e 56 anos em diante. Na comunidade de fala cuiabana, a distribuição em tempo aparente mostra uma tendência de mudança em progresso para algumas lexias. Algumas formas linguísticas em variação encontram-se em coexistência e concorrência com formas linguísticas mais antigas e representativas do falar cuiabano, as quais tendem a cair em desuso. A variante local conservadora, não padrão e estigmatizada, tende a ser substituída pela forma inovadora e de maior prestígio social. Em relação aos informantes nativos, o resultado da análise comparativa permite inferir, igualmente, que, em ambos os locais, há uma norma já consolidada, independente do grau de concorrência com outras variantes, visto que não houve diferença quando confrontadas 
as variantes selecionadas pelos nativos com a variante de maior frequência registada no corpus.

No que respeita ao léxico covilhanense, o exame da carta lexical permitiu evidenciar, por exemplo, i) a resistência de lexias de origem árabe; ii) a existência de lexias polissémicas: burro, corno, sósia. A exposição cartográfica dos dados permitiu, igualmente, constatar a diversidade do léxico cuiabano composto por i) tupinismos, como piranha, xará, pararaca, bituca, muquirana; ii) a existência de lexias polissémicas: matraca, gralha, puta, piranha, toco, vitrola; iii) regionalismos que recobrem todo o território brasileiro, como chifrudo, fofoqueira, fuxiqueira, vitrola, pão-duro, xará, pau-d'água, xilado, aldeia.

Esta análise evidenciou que os falares aludidos não se manifestaram, na sua essência, completamente distintos do léxico de outras regiões brasileiras e portuguesas, conforme pesquisa realizada no TLPGP, a qual permitiu constatar que os fenómenos linguísticos registados no corpus já estão documentados em trabalhos anteriores sobre o léxico do PB e do PE. Não há, portanto, nas variedades aqui descritas, peculiaridades linguísticas que possam individualizá-las e diferenciá-las de outras comunidades de fala brasileira ou portuguesa.

Acresce, ainda, que das variáveis extralinguísticas selecionadas como possíveis responsáveis pela implementação de formas linguísticas inovadoras e de maior prestígio sociolinguístico, os fatores "faixa etária", "nível de escolaridade" e "naturalidade", evidenciaram-se determinantes. De um modo geral, as percentagens mais elevadas são identificadas entre os informantes mais jovens, com nível de escolaridade média e superior e entre os inquiridos de outras regiões e/ou países. A variável género não se mostrou determinante na interpretação dos resultados quantitativos, para se atestar uma mudança em progresso, pelo que a oposição entre os géneros masculino e feminino é neutralizada neste contexto, em virtude do pressuposto de que não há propriamente 'linguagens' distintas de homens e mulheres e, sim, uma preferência por certos usos linguísticos em detrimento de outros.

A documentação cartográfica da variação lexical permitiu construir um quadro da diversidade semântico-lexical de duas áreas geográficas, mais especificamente, dos falares cuiabano e covilhanense, correlacionados com as variantes das questões propostas pelo QSL do ALiB. O estudo não permitiu, contudo, identificar um léxico específico do falar cuiabano, se comparado às variantes propostas pelo QSL do ALiB, visto que foi identificado um número pouco expressivo de variantes léxicas próprias da fala cuiabana. Pressupõe-se, portanto, que os traços linguísticos cuiabanos caminham em direção a um processo de arcaização, devido à uniformização do léxico local, com a 
implementação de lexias inovadoras de maior prestígio social, em detrimento daquelas que resultaram do processo de transmissão linguística irregular, desencadeado pelo contacto entre línguas no passado.

\section{Referências $^{3}$}

Álvarez, Rosario (coord.). s. a. Tesouro do léxico patrimonial galego e portugués. Santiago de Compostela: Instituto da Lingua Galega. http://ilg.usc.es/Tesouro [Acesso em 4.04.2020].

Atlas linguístico da Paraíba. s. a. https://alib.ufba.br/atlas-linguistico-da-paraiba-alpb [Acesso 4/04/2020].

Atlas linguístico do Brasil: questionários 2001(ALiB). 200I. Londrina: UEL.

Atlas linguístico-etnográfico de Portugal e da Galiza (ALEPG). s. a. https://www.clul. ulisboa.pt/pt/23-investigacao/68I-alepg-atlas-linguistico-etnografico-de-portugal-e-da-galiza [Acesso 4/04/2020].

Brandão, Silvia Figueiredo. I991. A geografia lingüística no Brasil. São Paulo: Ática.

Câmara Municipal da Covilhã. 20I4. http://www.cm-covilha.p/ [Acesso 4/04/2020].

Cintra, Luís Filipe Lindley. I995. Estudos de dialectologia portuguesa ( ${ }^{\mathrm{a}}$ ed.). Lisboa: Livraria Sá da Costa Editora.

Cunha, Celso \& Cintra, Luís Filipe Lindley. 200I. Nova gramática do português contemporâneo. Rio de Janeiro: Nova Fronteira.

Dicionário da língua portuguesa. 2014. Porto: Porto Editora.

Houaiss, Antônio \& Villar, Mauro de Salles. 20ıo. Dicionário Houaiss da língua portuguesa ( $4^{\mathrm{a}}$ ed.). Rio de Janeiro: Objetiva.

Muller, Charles. I968. Initiation à la statistique linguistique. Paris: Librarie Larousse.

\footnotetext{
3 Os autores das abonações retiradas dos diferentes Atlas, Dicionários ou Inquéritos Linguísticos não aparecem aqui referenciados, mas far-se-á apenas a referência ao Atlas, Dicionário ou Inquérito Linguístico de onde a abonação foi retirada (Ex: em "Apesar de não ter sido identificada na Covilhã, a lexia distrito na aceção de "Freguesia", integra o léxico do PE, em BaptistaF (I970: 592), por meio da variante destrito, anexa ao campo semântico "Povoamento, Instituições e Comunicações", conforme pesquisa realizada no Tesouro do Léxico Patrimonial Galego e Portugués", não é feita a referência a BaptistaF (I970: 592), mas ao Tesouro do Léxico Patrimonial Galego e Portugués (TLPGP) onde está inserta essa abonação.
} 


\section{Anexo I: Ficha da Localidade}

\begin{tabular}{|l|}
\hline 1. NOME OFICIAL: \\
\hline 2. COORDENADAS E LIMITES: \\
\hline 3. NOME REGIONAL: \\
\hline 4. NOMES ANTERIORES: \\
\hline 5. ATO DE CRIAÇÃO: \\
\hline 6. GENTÍLICO: \\
\hline 7. DISTÂNCIA DA CAPITAL: \\
\hline 8. COMO CHEGAR: \\
\hline 9. DADOS POPULACIONAIS E DENSIDADE DEMOGRÁFICA: \\
\hline 10. ATIVIDADES ECONÓMICAS PREDOMINANTES: \\
\hline 11. COMUNICAÇÕES: \\
\hline 12. HISTÓRICO SUSCINTO DA LOCALIDADE: \\
\hline 13. OBSERVAÇÕES GERAIS: \\
\hline
\end{tabular}




\section{Anexo II: Ficha do Sujeito}

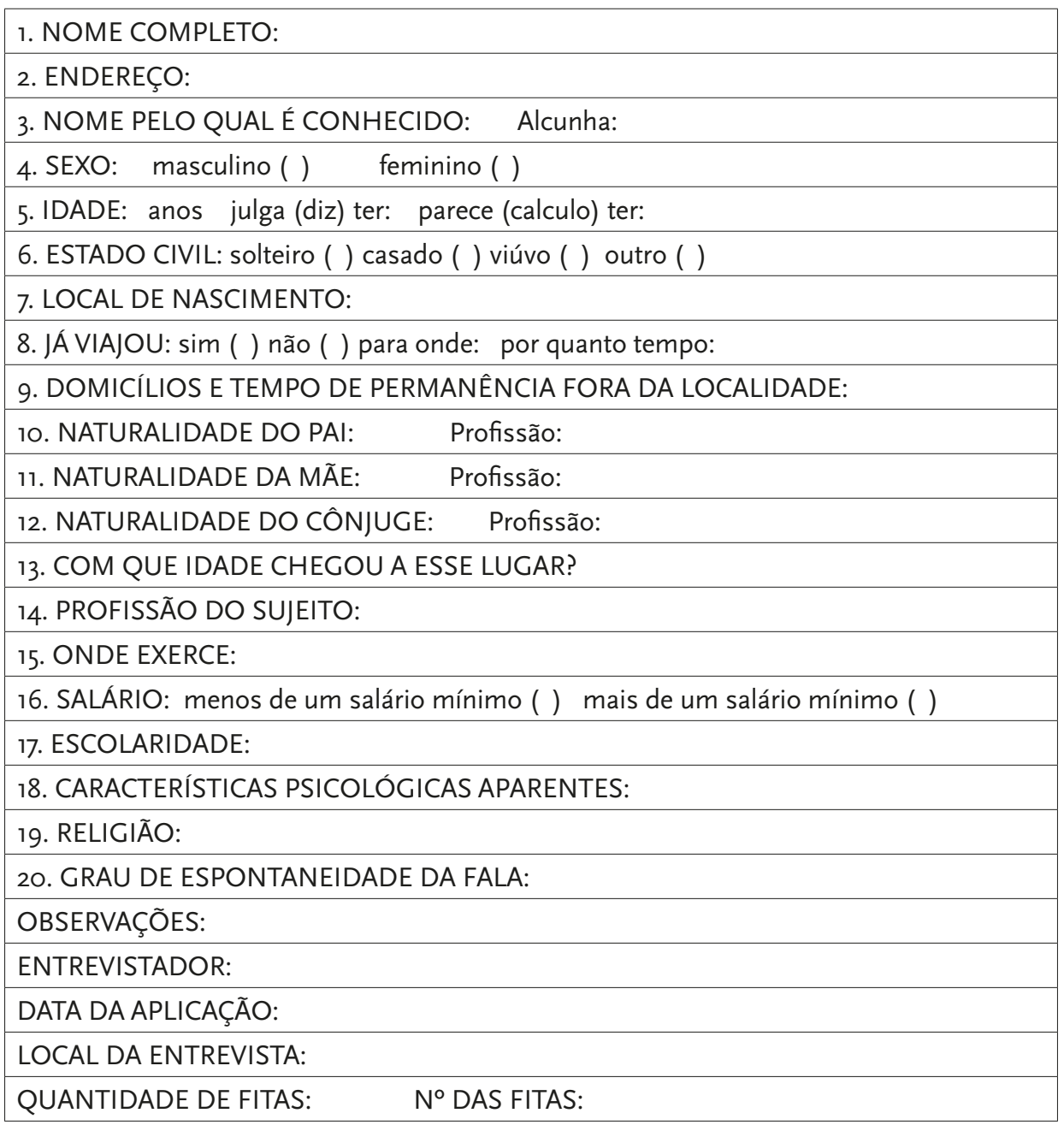




\section{Anexo III - QSL}

\section{7. "CONVÍVIO E COMPORTAMENTO SOCIAL"}

III. PESSOA TAGARELA

... a pessoa que fala demais?

II2. PESSOA POUCO INTELIGENTE

... a pessoa que tem dificuldade de aprender as coisas?

II3. PESSOA SOVINA

... a pessoa que não gosta de gastar seu dinheiro e, às vezes, até passa dificuldade para não gastar?

II4. MAU PAGADOR

... a pessoa que deixa suas contas penduradas?

II5. MARIDO ENGANADO

... o marido que a mulher passa para trás com outro homem?

II6. PROSTITUTA

... a mulher que se vende para qualquer homem?

II7. XARÁ

... a pessoa que tem o mesmo nome da gente?

ıI8. BÊBADO (DESIGNAÇÕES)

Que nomes dão a uma pessoa que bebeu demais?

II9. TOCO DO CIGARRO

... o resto do cigarro que se joga fora?

I20. AÇOUGUEIRO

... indivíduo que abate e esfola as reses nos matadouros?

I2I. CIDADE

... aglomeração humana localizada numa área geográfica circunscrita e que tem numerosas casas, próximas entre si, destinadas à moradia e/ou a atividades culturais, mercantis, industriais e financeiras?

I22. VILA

... povoação de categoria inferior a uma cidade, mas superior a uma aldeia. Um povoado pequeno?

I23. ALDEIA

... povoação de pequenas proporções, menor do que a vila. Povoação rural? 
